\title{
Gene expression of topoisomerase II alpha (TOP2A) by microarray analysis is highly prognostic in estrogen receptor (ER) positive breast cancer
}

\author{
A. Rody · T. Karn · E. Ruckhäberle · V. Müller • \\ M. Gehrmann · C. Solbach · A. Ahr · R. Gätje · \\ U. Holtrich · M. Kaufmann
}

Received: 29 February 2008 / Accepted: 29 February 2008/Published online: 14 March 2008

(C) Springer Science+Business Media, LLC. 2008

\begin{abstract}
Introduction Overexpression of Topoisomerase II alpha (TOP2A) has been implicated with gene amplification of the 17q21 amplicon and consecutively with ErbB2 overexpression and amplification. However, gene amplification does not necessarily correlate with RNA and protein expression. There is growing evidence that TOP2A protein expression is a strong prognostic and TOP2A gene amplification might be a predictive marker (particularly for the use of anthracyclines). Methods Large scale analysis was performed using Affymetrix microarray data from $n=1,681$ breast cancer patients to evaluate TOP2A expression. Results TOP2A expression showed a strong correlation with tumor size $\left(\chi^{2}\right.$-test, $\left.P<0.001\right)$, grading $(P<0.001)$, ErbB2 $(P<0.001)$ and Ki67 expression $(P<0.001)$ as well as nodal status $(P=0.042)$. Survival analysis revealed a significant prognostic value in ER positive $(n=994$; log rank $P<0.001$ ), but not in ER negative breast cancer patients ( $n=369, P=0.35$ ). The prognostic impact of TOP2A expression was independent of Ki67 expression in ER
\end{abstract}

A. Rody and T. Karn contributed equally to this work.

Electronic supplementary material The online version of this article (doi:10.1007/s10549-008-9964-x) contains supplementary material, which is available to authorized users.

A. Rody $(\bowtie) \cdot$ T. Karn · E. Ruckhäberle · C. Solbach ·

A. Ahr · R. Gätje · U. Holtrich · M. Kaufmann

Department of Obstetrics and Gynecology, J. W. Goethe

University, Theodor-Stern-Kai 7, D-60590 Frankfurt, Germany

e-mail: achim.rody@em.uni-frankfurt.de

V. Müller

Department of Obstetrics and Gynecology,

University of Hamburg, Hamburg, Germany

M. Gehrmann

Siemens Diagnostics, Leverkusen, Germany positive tumors $(P=0.002$ and $P=0.007$ for high and low Ki67, respectively). Moreover a worse prognosis of high TOP2A expressing tumors was found in the subgroup of ErbB2 negative tumors $(P<0.001)$ and a trend among ErbB2 positive tumors $(P=0.11)$. The prognostic value of TOP2A was independent of whether the patients were untreated or had received adjuvant therapy. In multivariate Cox regression analysis including standard parameters TOP2A emerged to be the top prognostic marker (HR $2.40,95 \%$ CI $1.68-3.43, P<0.001)$. Conclusion TOP2A expression is an independent prognostic factor in ER positive breast cancer and could be helpful for risk assessment in ER positive breast cancer patients.

Keywords Breast breast cancer - Microarray analysis . Prognosis · Topoisomerase II alpha

\section{Introduction}

Topoisomerase II alpha (TOP2A) is a key enzyme in DNA replication and a target of various cytotoxic agents such as anthracyclines. The gene is located on chromosome $17 \mathrm{q} 21$ in close proximity to the ErbB2 locus and encodes for 170kilodalton protein, which catalyzes the unwinding of DNA by inducing single-stranded breaks on both DNA strands. Anthracyclines, one of the most effective cytotoxic agents used in the treatment of breast cancer patients, inhibit TOP2A by trapping the DNA strand intermediates and leading to persistent DNA cleavage [1]. Several metaanalyses of breast cancer which have been reviewed very recently $[2,3]$ demonstrate that response to anthracycline containing chemotherapy seems to be significant better for ErbB2 positive tumors. As a simple straight forward explanation it had been previously suggested that ErbB2 
amplification might in fact be a surrogate marker for coamplification of the TOP2A gene in this setting. However, while results from in vitro analysis and several clinical studies were in line with this model other studies did not confirm this hypothesis [4-8]. The uncertainty regarding the biologic relationship between TOP2A protein expression, copy number, proliferation, and benefit from anthracylines makes assessment of TOP2A unreliable at this time [3]. In fact, recent trials suggest that the model of a direct relationship between TOP2A amplification, overexpression of TOP2A protein, and benefit from anthracyclines is overly simplistic $[10,11]$. Thus, although there is a stronger theoretical underpinning for a relationship between the TOP2A gene and in particular its protein product and anthracycline efficacy, there are as much or more data supporting the role of HER2 in predicting differential anthracycline benefit $[2,12]$. However, while not yet published, data of 2990 ErbB2 positive patients from the second interim analysis of the BCIRG 006 trial had been interpreted to suggest that those 1,057 (35\%) patients with TOP2A co-amplification may not require trastuzumab in addition to an anthracycline-containing regimen [13]. The analysis of a potential predictive value of TOP2A protein expression is further complicated by the fact that TOP2A protein expression is a strong prognostic factor. Studies have shown that TOP2A protein expression as detected by immunohistochemistry is associated with ER negativity, a higher histological grade and proliferative state of the tumor as well as poor survival [14-16]. While TOP2A gene amplification does not correlate with protein expression as detected by immunohistochemistry $[14,15]$ it is less clear whether steady state mRNA levels of the TOP2A gene might better correlate to its amplification. Here we investigated expression levels of TOP2A mRNA by Affymetrix microarray analysis in a combined large scale breast cancer cohort and its prognostic impact. Since clear cut-off levels for high and low TOP2A expression are not available we choose a conservative approach using a median split of expression values. Furthermore tumor samples were stratified according to ER, ErbB2 and Ki67 expression.

\section{Materials and methods}

Analysis of breast cancer microarray datasets

We established a database consisting of 1,681 Affymetrix microarray datasets from primary breast cancer patients without neoadjuvant treatment. We included 220 of our own samples (datasets Frankfurt and Hamburg) which have been described previously [17-20] as well as 1,461 samples from nine different publicly available datasets (Table 1): Uppsala [21], Stockholm [22], Rotterdam [23, 24], Oxford-

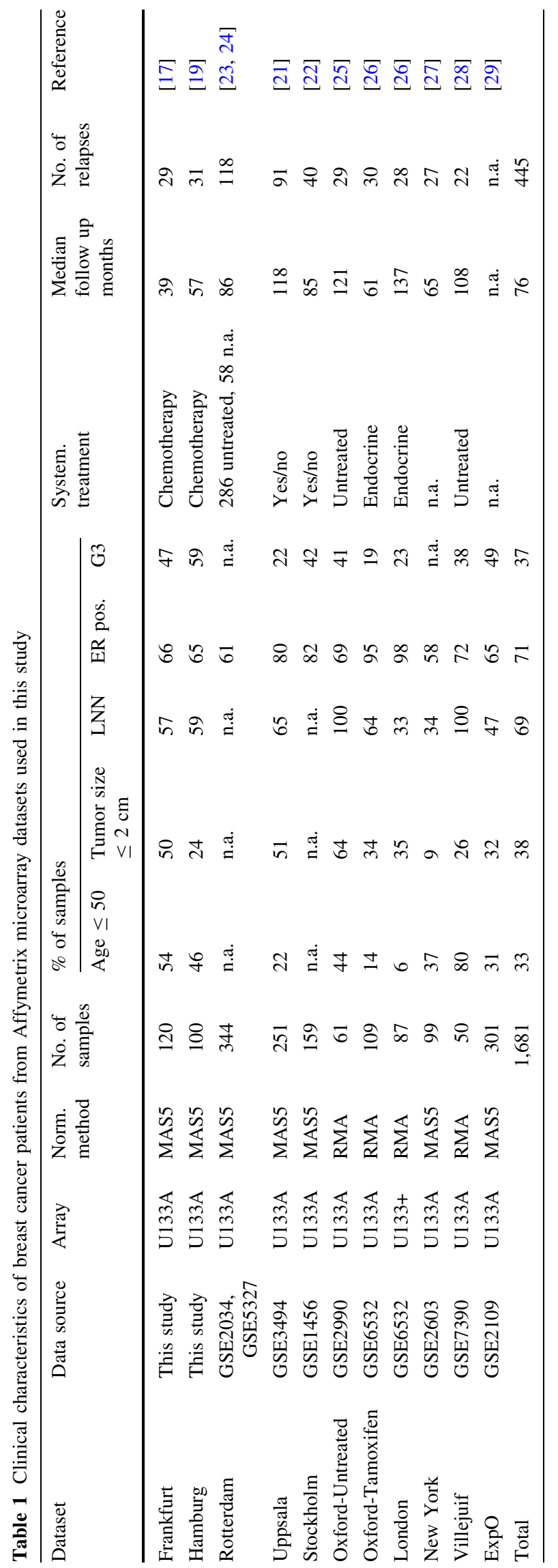


Untreated [25], Oxford-Tamoxifen and London [26], NewYork [27], Villejuif [28], and ExpO [29]. For comparability only data from Affymetrix HG-U133A microarrays were used. The clinical characteristics of the patients in the different datasets are given in Table 1. Follow up information was available for 1,363 patients. The median followup time was 76 months. 1,200 of the 1,681 samples were ER positive. Treatment information could be obtained for 878 ER positive and 262 ER negative patients. Since methods of Affymetrix microarray normalization can have significant effects on the levels for individual probe sets, several uniform normalization methods [30, 31] of CEL file data has been developed to allow the analysis of sets of multiple arrays. However, important discrepancies between different datasets depend on the dynamics of the measurements originating from different hybridization efficiencies. Unfortunately even uniform normalization methods are incapable in compensating those experimental differences. In addition, for some studies (e.g. the Rotterdam dataset) no CEL files are available. Therefore, in the analysis presented here we used a conservative strategy for dataset stratification by relying on a ranking of samples in each cohort. Each dataset of microarrays was normalized separately using the originally proposed method in the respective study (see Table 1). Log transformed expression values were median centered over each array. For genes the normalization, ranking of expression values and median splits were done separately in each dataset.

Assessment of ER, ErbB2, proliferative status and TOP2A expression of the samples

To allow comparison of different datasets and since standard pathology for ER and ErbB2 was not available for all samples, receptor status was determined based on Affymetrix expression data as previously described [3235]. The estrogen receptor status was determined using Affymetrix probe set 205225_at, the ErbB2 status using Affymetrix probe set 216836_s_at. A specificity of $86.1 \%$ and a sensitivity of $92.2 \%$ was observed when the chip based ER status was compared to immunohistochemical obtained ER status (available for 1,333 samples), while the specificity and sensitivity of chip based ErbB2 status was $98.6 \%$ and $45.8 \%$, respectively, compared to $3+$ staining in immunohistochemistry with HER2 antibody (data available for 206 samples). As a surrogate marker for cellular proliferation we used the expression of the proliferation marker Ki67 (ProbeSets 212020-212023_s_at). Appropriate cut off values that distinguish between high and low proliferative activity in a clinically relevant manner using Ki67 immunohistochemistry in breast cancer have not been universally established [36]. Thus, a conservative median split according to $\mathrm{Ki} 67$ gene expression was applied which corresponds to a percentage of MIB-1 positive cells of 16-17\% [37]. To allow comparison of TOP2A expression between different datasets we used a median split of each dataset according to TOP2A Affymetrix data (ProbeSets 201291_s_at, 201292_at). An exploratory analysis revealed a significant higher TOP2A expression in ER negative cancers. Thus to avoid a confounding effect by the ER status in further analyses only ER positive tumor samples were used (see Results). For those analyses the median split of TOP2A was applied only to the ER positive subgroup to prevent a confounding effect of the relative proportions of ER positive and negative tumors in the different datasets.

\section{Statistical analysis}

Subjects with missing values were excluded from the analyses and all reported $P$ values are two sided. $P$ values of less than 0.05 were considered to indicate a significant result. Chi-square test was used for categorical parameters. Survival intervals were measured from the time of surgery to the time of death from disease or of the first clinical or radiographic evidence of disease recurrence. Data for women in whom the envisaged end point was not reached were censored as of the last follow-up date or at 120 months. We constructed Kaplan-Meier curves and used the log rank test to determine the univariate significance of the variables. A Cox proportional-hazards regression model was used to examine simultaneously the effects of multiple covariates on survival. The effect of each variable was assessed with the use of the Wald test and described by the hazard ratio, with a 95 percent confidence interval. The model included age, tumor size, lymph node status, ER, ErbB2, Ki67 as well as TOP2A expression. All analyses were performed using SPSS 15.0 (SPSS Inc., Chicago, IL).

\section{Results}

Analysis of TOP2A Affymetrix expression data in a combined cohort of 1,681 breast cancers

Gene expression values of $n=1,681$ patients from 11 different datasets were analyzed (see Table 1). TOP2A is represented by two different ProbeSets on the Affymetrix HGU133A microarray. Figure 1a displays the high correlation of the expression values from the two ProbeSets in a scatter plot of the measurements from the combined cohort. Thus, in subsequent analyses the mean of both ProbeSets was applied. An initial exploratory analysis revealed a significant higher expression of TOP2A in ER negative breast cancers $(n=481)$ compared to ER positive tumors ( $n=1200$ ) (Mann Whitney $P<0.001$, Fig. 1b). In addition ErbB2 positive tumors displayed a higher expression of 
Fig. 1 (a) Scatter plot of TOP2A expression values obtained from two different ProbeSets on the Affymetrix HG-U133A microarray for 1681 samples. (b) Difference in TOP2A expression between tumors with positive and negative ER status, respectively. (c) Comparison of TOP2A expression of ErbB2 positive and negative tumors stratified by ER status
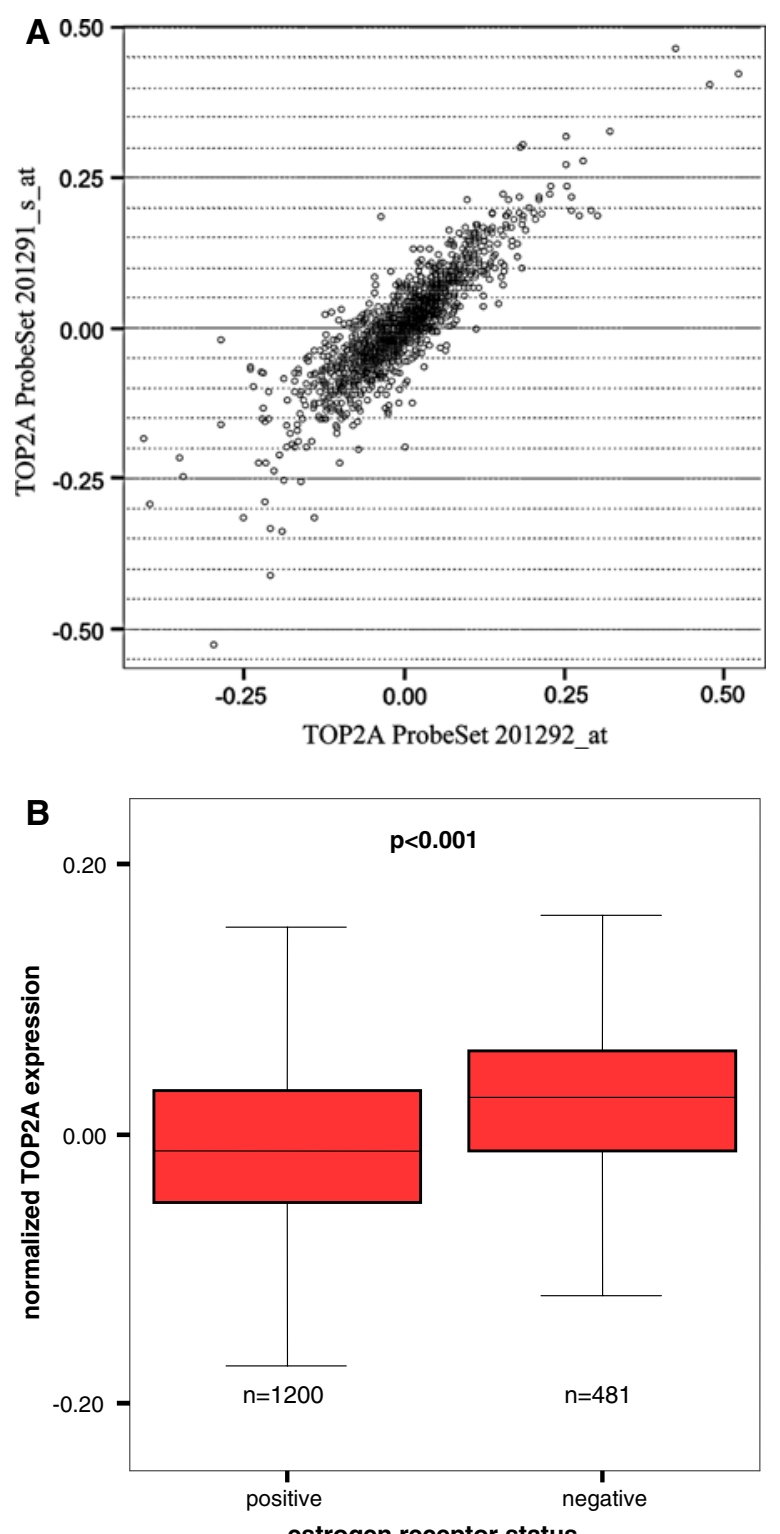

estrogen receptor status
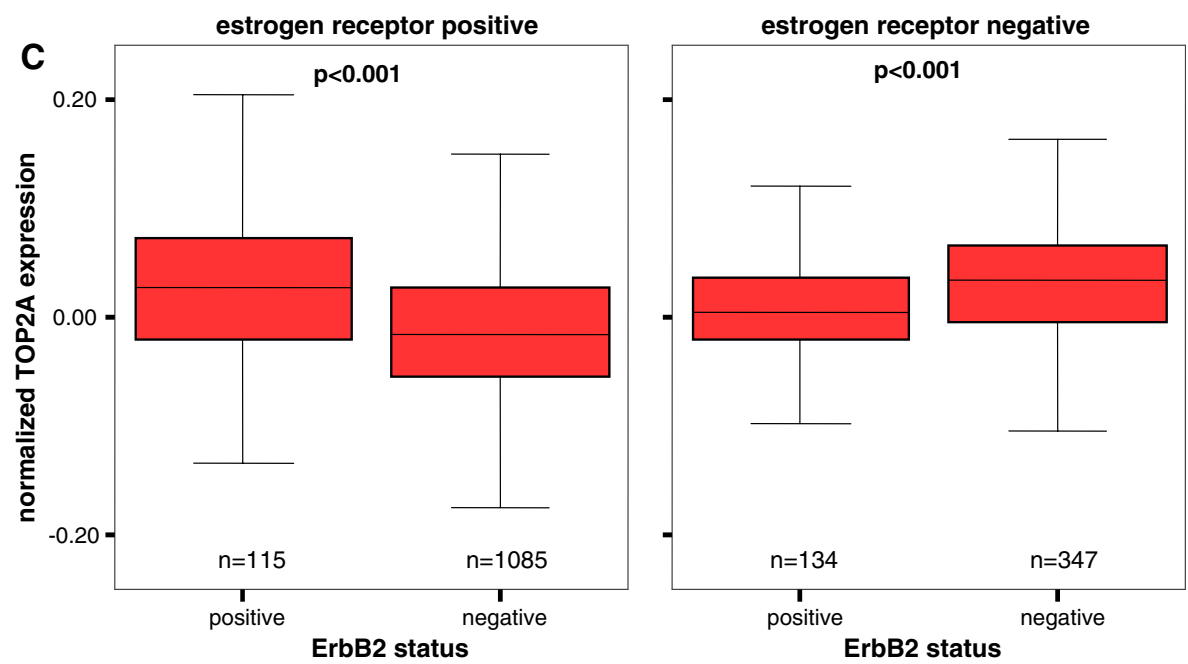
TOP2A in the ER positive subgroup. However the latter was not observed when comparing ER negative tumors which are ErbB2 positive and negative, respectively (Fig. 1c). The ER status had a larger impact on the distribution of TOP2A expression (see Supplementary Figure S1). Thus, to avoid a confounding effect of the ER status we subsequently used separate median splits of TOP2A values for ER positive and negative cohorts, respectively.

Analysis of the prognostic impact of TOP2A expression in ER positive and negative breast cancers

ER negative tumors showed no difference in survival when stratified according to high or low TOP2A expression $(P=0.35)$ even when they were analyzed separately with respect to their ErbB2 status (data not shown). In contrast, as shown in Fig. 2, a highly significant difference in disease free survival (DFS) was observed for ER positive breast cancers ( $n=994$ with follow up) when they were stratified according to TOP2A expression. While the 5 year DFS of patients with ER positive tumors with low TOP2A expression was $83.8 \pm 1.7 \%$, that of patients whose ER positive tumors displayed high TOPO2 expression was only $67.0 \pm 2.0 \%(P<0.001)$.

Correlation of TOP2A expression with clinical characteristics among ER positive breast cancers

Due to the worse impact of TOP2A expression on the prognosis of patients with ER positive tumors we further analyzed the clinical characteristics of those patients. The clinical parameters of ER positive breast cancers stratified according to high and low TOP2A expression are presented in Table 2. High TOP2A expression is associated with larger tumor size $\left(\chi^{2}\right.$-test, $\left.P<0.001\right)$, node positive disease $(P=0.042)$, poor histological grading $(P<0.001)$ and high proliferative activity $(P<0.001)$. Moreover as shown above (see Fig. 1c) a positive correlation of TOP2A and ErbB2 expression was observed for ER positive tumors which might be due to an co-amplification of the $17 \mathrm{q} 21$ amplicon. $71.3 \%$ of the ErbB2 positive samples were found in the group with high TOP2A expression. However, these ErbB2 positive samples represent only 82/603 (13.6\%) of all tumors in the TOP2A high group and those tumors with highest TOP2A expression are not identical to the ErbB2 positive subset suggesting that TOP2A expression is not exclusively caused by $17 \mathrm{q} 21$ amplification.

Prognostic value of TOP2A among ER positive breast cancers with high and low proliferation

A median split of the samples according to Ki67 expression was used as a surrogate marker for stratifying tumors into
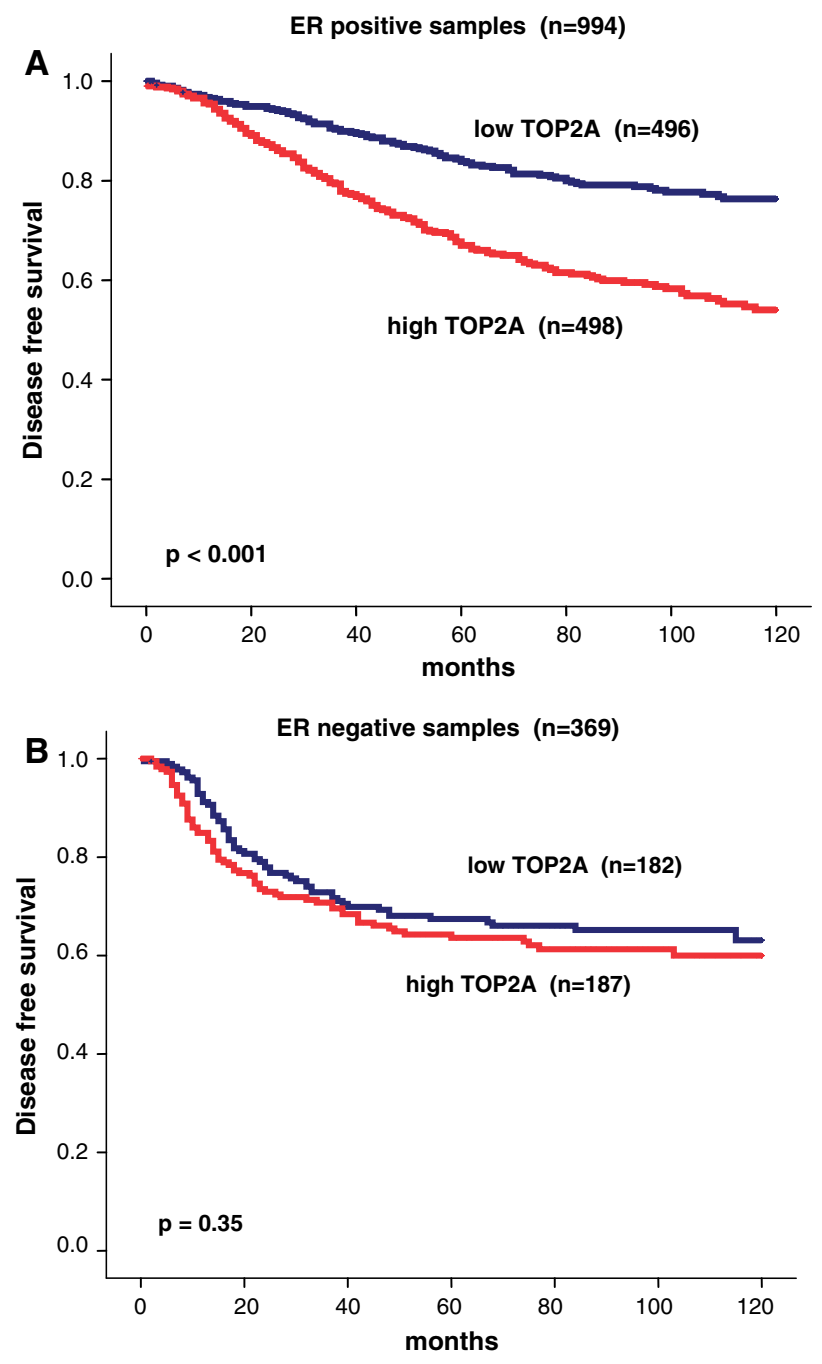

Fig. 2 Prognostic value of TOP2A expression in ER positive and negative tumors. (a) Diseases free survival of ER positive breast cancers $(n=994)$ stratified by a median split of TOP2a expression (for 206 of 1200 patients no follow up data were available, see Table 1). (b) Disease free survival of ER negative breast cancers $(n=369)$ stratified by a median split of TOP2a expression (for 112 of 481 patients no follow up data were available, see Table 1)

groups with high and low proliferation. TOP2A expression was associated with higher expression of $\mathrm{Ki} 67.76 \%$ of tumors with Ki67 above the median did also show high TOP2A expression (Table 2, $P<0.001$ ). For both subgroups of tumors according to Ki67 expression a significant better prognosis for those patients with low TOP2A expression was obtained (Ki67 low: $P=0.002$; Ki67 high: $P=0.007$, Fig. 3). This suggests that TOP2A expression adds prognostic information to Ki67 in ER positive breast cancers.

Prognostic value of TOP2A among ER positive breast cancers stratified by ErbB2 status

Of the 994 ER positive tumors with follow up data 97 (9.8\%) were classified as ErbB2 positive. Within this 
Table 2 Clinical parameters of ER positive breast cancers stratified according to high and low TOP2A expression

\begin{tabular}{|c|c|c|c|c|c|}
\hline & & \multirow{2}{*}{$\begin{array}{l}\text { Total } \\
n=1200\end{array}$} & \multicolumn{2}{|l|}{ TOP2A } & \multirow[t]{2}{*}{$P$-value } \\
\hline & & & $\begin{array}{l}\text { Low } \\
n=597(49.8 \%)\end{array}$ & $\begin{array}{l}\text { High } \\
n=603(50.2 \%)\end{array}$ & \\
\hline \multirow[t]{2}{*}{ Tumor size* } & $\leq 2 \mathrm{~cm}$ & 322 & $189(58.7 \%)$ & $133(41.3 \%)$ & \multirow[t]{2}{*}{$<0.001$} \\
\hline & $>2 \mathrm{~cm}$ & 470 & $202(43.0 \%)$ & $268(57.0 \%)$ & \\
\hline \multirow[t]{2}{*}{ Nodal status** } & Node negative & 664 & $344(51.8 \%)$ & $320(48.2 \%)$ & \multirow[t]{2}{*}{0.042} \\
\hline & Node positive & 324 & $145(44.8 \%)$ & $179(55.2 \%)$ & \\
\hline \multirow[t]{2}{*}{ Histological grading ${ }^{\mathrm{a}}$} & Grade1, 2 & 599 & $350(58.4 \%)$ & $249(41.6 \%)$ & \multirow[t]{2}{*}{$<0.001$} \\
\hline & Grade 3 & 200 & $43(21.5 \%)$ & $157(48.5 \%)$ & \\
\hline \multirow[t]{2}{*}{$\mathrm{Age}^{\mathrm{b}}$} & $\leq 50$ & 255 & $121(47.5 \%)$ & $134(52.5 \%)$ & \multirow[t]{2}{*}{0.37} \\
\hline & $>50$ & 591 & $301(50.9 \%)$ & $290(49.1 \%)$ & \\
\hline \multirow[t]{2}{*}{ ErbB2 } & ErbB2 low & 1085 & $564(52.0 \%)$ & $521(48.0 \%)$ & \multirow[t]{2}{*}{$<0.001$} \\
\hline & ErbB2 high & 115 & $33(28.7 \%)$ & $82(71.3) \%)$ & \\
\hline \multirow[t]{2}{*}{ Ki67 } & Ki67 low & 597 & $458(76.7 \%)$ & $139(23.3 \%)$ & \multirow[t]{2}{*}{$<0.001$} \\
\hline & Ki67 high & 603 & $139(23.1 \%)$ & $464(76.9 \%)$ & \\
\hline
\end{tabular}

* Information on tumor size was not available for $n=408$ patients

** Information on nodal status was not available for $n=212$ patients

${ }^{\text {a }}$ Information on tumor grade was not available for $n=401$ patients

${ }^{b}$ Information on age was not available for $n=354$ strongest prognostic marker for disease free survival (HR $2.40,95 \%$ CI $1.68-3.43, P<0.001)$ beside tumor size (HR $0.48,95 \%$ CI $0.34-0.69, P<0.001$ ) and ErbB2 status (HR $1.90,95 \%$ CI $1.19-3.02, P=0.007)$.

\section{Discussion}

ErbB2 amplification has been corroborated as a predictive factor for response to anthracycline containing chemotherapy [2]. Since the topoisomerase II alpha protein is a direct target for anthracyclines in vitro it has been suggested that ErbB2 is only a surrogate marker for coamplification of the TOP2A gene. However, expression of TOP2A protein product as measured by immunohistochemistry does not correlate with amplification of the TOP2A gene but rather with cellular proliferation [14]. Fritz et al. [15] observed an overexpression of TOP2A protein using immunohistochemistry in approximately $25 \%$, whereas overexpression of both c-ErbB2 and TOP2A could be detected in only $9.3 \%$ of breast cancers. TOP2A and c-ErbB2 were found to be overexpressed in overlapping but distinct subgroups of patients. Moreover, the authors found a prognostic impact of TOP2A protein, which was confined to the subgroup of hormone receptor positive patients. It could be suggested that immunohistochemistry is inaccurate in measuring quantitative steady state levels of TOP2A in tumors with or without Top2agene-amplification. Unlike the expression of ErbB2, TOP2A expression is highly regulated at transcriptional and translational level [38, 39], suggesting that gene amplification may not have a profound effect on the total amount of TOP2A protein in the cell. Here we could show in a large cohort that TOP2A mRNA expression levels as detected by microarray analysis are also strongly 

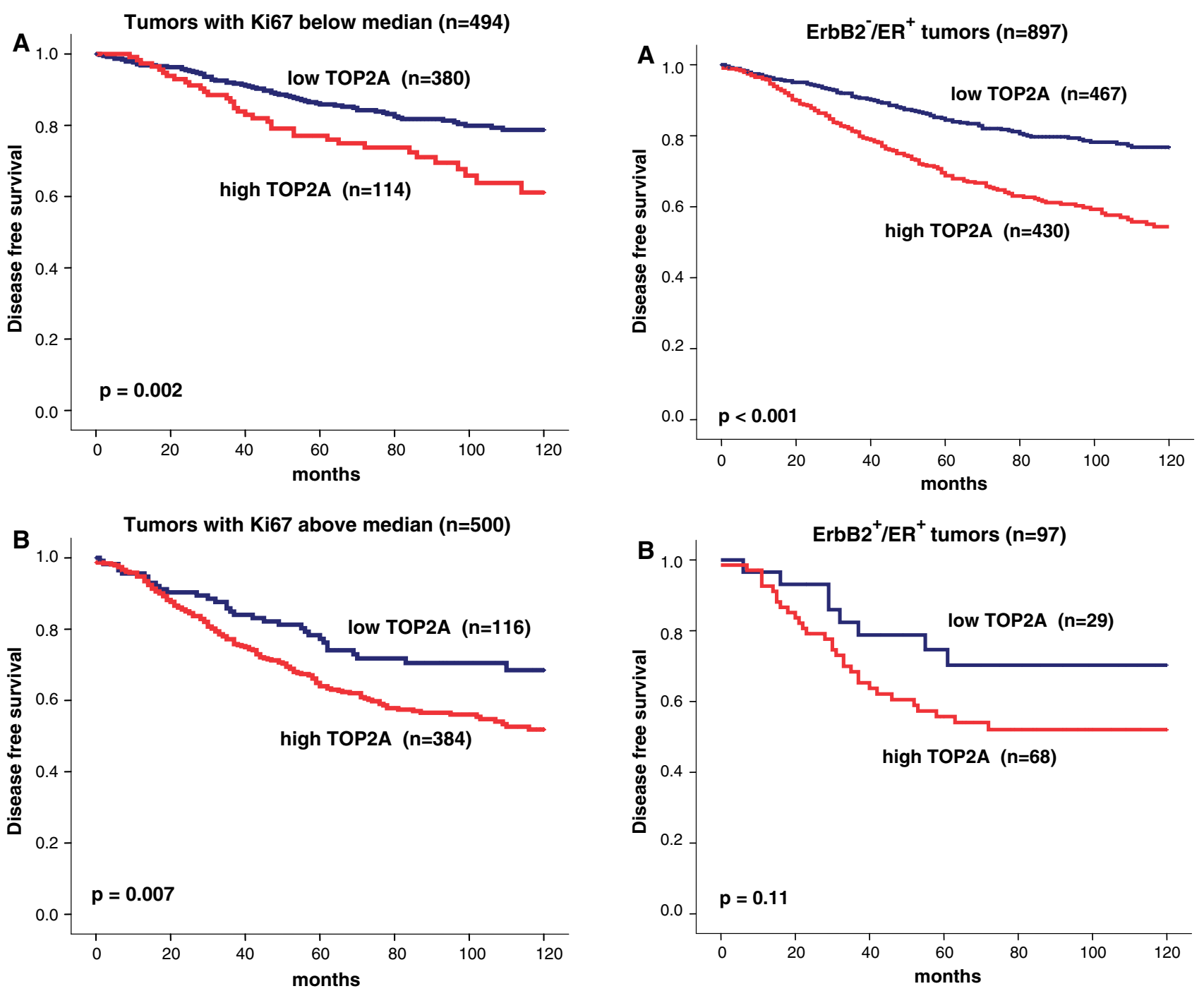

Fig. 3 Prognostic value of TOP2A expression in ER positive tumors with high and low proliferation, respectively, as measured by Ki67 expression. (a) Disease free survival of ER positive breast cancers with Ki67 below the median $(n=494)$ stratified by TOP2a expression. (b) Disease free survival of ER positive breast cancers with median Ki67 or above $(n=500)$ stratified by TOP 2 a expression

associated with cellular proliferation, ER negativity and a worse prognosis as has been shown for TOP2A protein expression [14-16]. Our data clearly demonstrate that TOP2A expression as measured by microarray analysis has a high prognostic value in ER positive breast cancer patients. Multivariate analysis of standard parameters and TOP2A in ER positive breast cancers revealed, that high TOP2A and ErbB2 expression, as well as tumor size remain the only independent parameters for predicting poor survival. In contrast TOP2A expression was not a prognostic factor in ER negative tumors which is in perfect agreement with the data of Fritz et al. [15], who could demonstrate similar results by using immunohistochemistry. For this reason we further analyzed the subgroup of ER

Fig. 4 Prognostic value of TOP2A expression in ER positive tumors according to ErbB2 status. (a) Disease free survival of ErbB2 negative, ER positive breast cancers $(n=897)$ stratified by TOP2a expression. (b) Disease free survival of ErbB2 positive, ER positive breast cancers $(n=97)$ stratified by TOP2a expression

positive breast cancers. Mueller et al. [14] had demonstrated that TOP2A protein expression is strongly correlated with Ki67 expression. Our data support this observation since higher expression values of TOP2A were associated with Ki67 gene expression (Supplementary Figure S2). However, TOP2A expression maintained its strong prognostic significance in both groups with high and low Ki67 expression. In this context it should be considered that cell cycle activity and DNA ploidy may have different implications with regards of tumor response to chemotherapy [40]. Hannemann et al. could not observe a significant benefit from anthracycline containing high dose chemotherapy in breast cancer patients with TOP2A amplification [41] which adds to our data in the neoadjuvant setting [12]. 

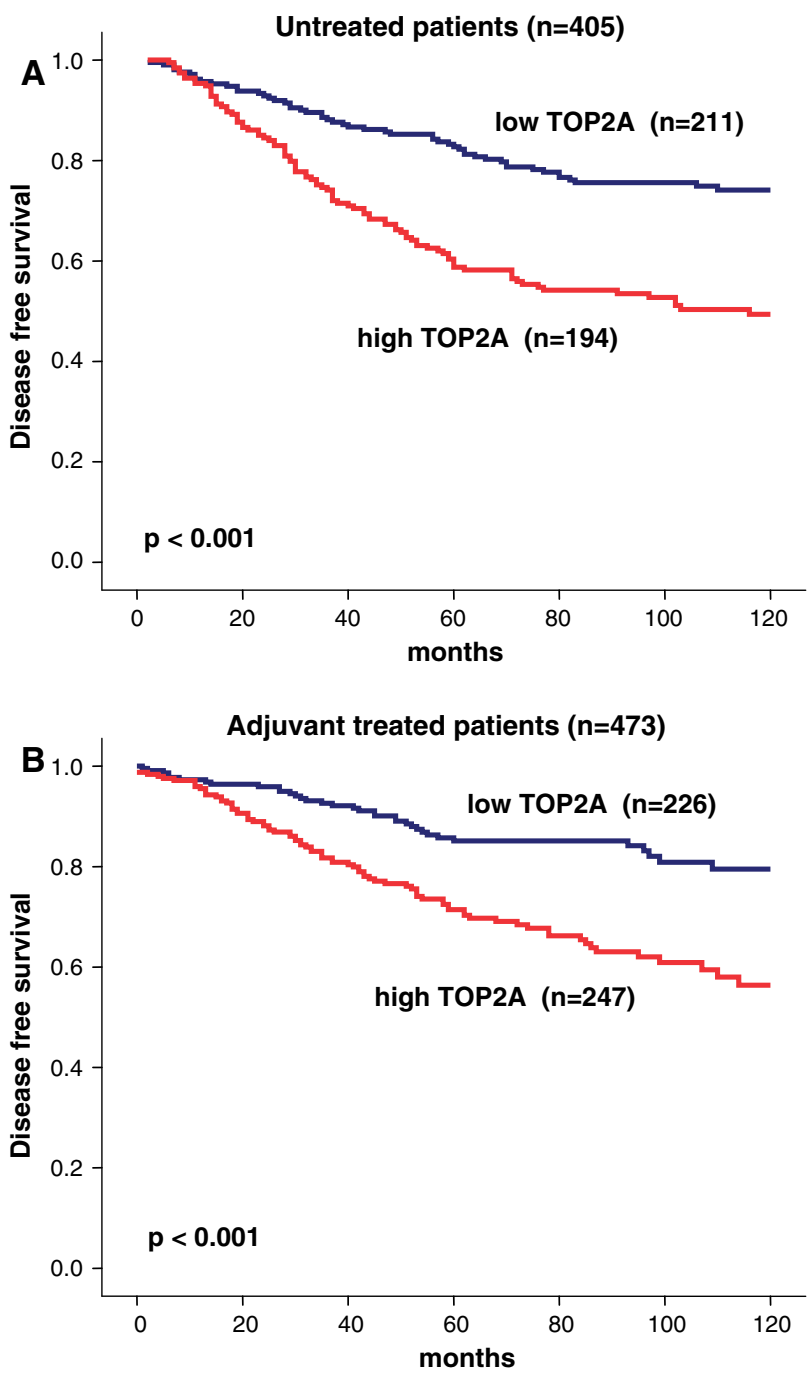

Fig. 5 Prognostic value of TOP2A expression in ER positive tumors according to adjuvant treatment. (a) Disease free survival of ER positive breast cancers without any adjuvant treatment $(n=405)$ stratified by TOP2a expression. (b) Disease free survival of adjuvant treated ER positive breast cancers $(n=473)$ stratified by TOP2a expression

Regarding a possible predictive value of TOP2A our data demonstrate that TOP2A remains a strong prognostic marker in untreated and adjuvant treated patients. All these observations raise the question if prediction of anthracycline sensitivity is rather caused by higher proliferation (associated with high levels of TOP2A RNA) than TOP2A amplification or if the predictive value in terms of anthracycline sensitivity might be induced by other markers adjacent to the 17q21 amplicon. To date no concise data with regards to these topics are available.

In conclusion, this large scale analysis of gene expression data in ER positive breast cancer patients demonstrates a strong prognostic impact of TOP2A expression, outperforming standard parameters as tumor size, nodal status,
Table 3 Multivariate Cox regression analysis of standard parameters and TOP2a expression in relation to disease free survival among ER positive breast cancers

\begin{tabular}{|c|c|c|c|c|c|}
\hline Parameter & & $n$ & $\begin{array}{l}P \\
\text { value }\end{array}$ & $\begin{array}{l}\text { Hazard } \\
\text { ratio }\end{array}$ & $(95 \% \mathrm{CI})$ \\
\hline $\begin{array}{l}\text { TOP2A } \\
\quad \text { expression }\end{array}$ & High vs. low & $\begin{array}{c}275 \text { vs. } \\
266\end{array}$ & 0.0000 & 2.40 & $(1.68-3.43)$ \\
\hline Nodal status & $\begin{array}{l}\text { Positive } \\
\text { vs. } \\
\text { negative }\end{array}$ & $\begin{array}{c}199 \text { vs. } \\
342\end{array}$ & 0.7046 & 1.07 & $(0.76-1.49)$ \\
\hline Age & $\leq 50$ vs. $>50$ & $\begin{array}{c}173 \text { vs. } \\
368\end{array}$ & 0.9622 & 1.01 & $(0.71-1.43)$ \\
\hline $\begin{array}{l}\text { Histological } \\
\text { grading }\end{array}$ & $\begin{array}{l}\text { Poor } \\
\quad \text { vs. well/ } \\
\text { intermediate }\end{array}$ & $\begin{array}{c}117 \text { vs. } \\
424\end{array}$ & 0.5502 & 1.12 & $(0.77-1.62)$ \\
\hline Tumor size & $\begin{array}{c}\leq 2 \mathrm{~cm} \text { vs. } \\
>2 \mathrm{~cm}\end{array}$ & $\begin{array}{c}241 \text { vs. } \\
300\end{array}$ & 0.0001 & 0.48 & $(0.34-0.69)$ \\
\hline $\begin{array}{l}\text { ErbB2 } \\
\quad \text { expression }\end{array}$ & High vs. low & $\begin{array}{c}45 \text { vs. } \\
496\end{array}$ & 0.0069 & 1.90 & $(1.19-3.02)$ \\
\hline
\end{tabular}

Data available from $n=541$ patients

Significant $P$ values are given in bold

grading, age and ErbB2. Our data show that this marker could be helpful for risk assessment in ER positive breast cancer patients. A prospective evaluation and standardized method of measuring TOP2A would be useful to verify these observations.

Acknowledgements We thank Katherina Kourtis and Samira Adel for expert technical assistance. This work was supported by grants from the Deutsche Krebshilfe, the Margarete Bonifer-Stiftung, Bad Soden, the BANSS-Stiftung, Biedenkopf, and the Dr. Robert PflegerStiftung, Bamberg.

\section{References}

1. Wang JC (2002) Cellular roles of DNA topoisomerases: a molecular perspective. Nat Rev Mol Cell Biol 3(6):430-440

2. Pritchard KI, Messersmith H, Elavathil L, Trudeau M, O'Malley F, Dhesy-Thind B (2008) HER-2 and topoisomerase II as predictors of response to chemotherapy. J Clin Oncol 26(5):736-744

3. Gennari A, Sormani MP, Pronzato P, Puntoni M, Colozza M, Pfeffer U, Bruzzi P (2008) HER2 status and efficacy of adjuvant anthracyclines in early breast cancer: a pooled analysis of randomized trials. J Natl Cancer Inst 100(1):14-20

4. Di Leo A, Gancberg D, Larsimont D, Tanner M, Jarvinen T, Rouas G, Dolci S, Leroy JY, Paesmans M, Isola J, Piccart MJ (2002) HER-2 amplification and topoisomerase IIalpha gene aberrations as predictive markers in node-positive breast cancer patients randomly treated either with an anthracycline-based therapy or with cyclophosphamide, methotrexate, and 5-fluorouracil. Clin Cancer Res 8(5):1107-1116

5. Coon JS, Marcus E, Gupta-Burt S, Seelig S, Jacobson K, Chen S, Renta V, Fronda G, Preisler HD (2002) Amplification and overexpression of topoisomerase IIalpha predict response to anthracycline-based therapy in locally advanced breast cancer. Clin Cancer Res 8(4):1061-1067 
6. Cardoso F, Durbecq V, Larsimont D, Paesmans M, Leroy JY, Rouas G, Sotiriou C, Renard N, Richard V, Piccart MJ, Di Leo A (2004) Correlation between complete response to anthracyclinebased chemotherapy and topoisomerase II-alpha gene amplification and protein overexpression in locally advanced/metastatic breast cancer. Int J Oncol 24(1):201-209

7. Tanner M, Isola J, Wiklund T, Erikstein B, Kellokumpu-Lehtinen P, Malmström P, Wilking N, Nilsson J, Bergh J (2006) Topoisomerase IIalpha gene amplification predicts favorable treatment response to tailored and dose-escalated anthracycline-based adjuvant chemotherapy in HER-2/neu-amplified breast cancer: Scandinavian Breast Group Trial 9401. J Clin Oncol 24(16): 2428-2436

8. Arriola E, Moreno A, Varela M, Serra JM, Falo C, Benito E, Escobedo AP (2006) Predictive value of HER-2 and Topoisomerase IIalpha in response to primary doxorubicin in breast cancer. Eur J Cancer 42(17):2954-2960

9. Harris L, Fritsche H, Mennel R, Norton L, Ravdin P, Taube S, Somerfield MR, Hayes DF, Bast RC Jr (2007) American Society of Clinical Oncology. American Society of Clinical Oncology 2007 update of recommendations for the use of tumor markers in breast cancer. J Clin Oncol 25(33):5287-5312

10. Knoop AS, Knudsen H, Balslev E, Rasmussen BB, Overgaard J, Nielsen KV, Schonau A, Gunnarsdóttir K, Olsen KE, Mouridsen H, Ejlertsen B (2005) Danish Breast Cancer Cooperative Group. Retrospective analysis of topoisomerase IIa amplifications and deletions as predictive markers in primary breast cancer patients randomly assigned to cyclophosphamide, methotrexate, and fluorouracil or cyclophosphamide, epirubicin, and fluorouracil: Danish Breast Cancer Cooperative Group. J Clin Oncol 23(30): 7483-7490

11. O'Malley FP, Chia S, Tu D et al (2006) Topoisomerase II alpha protein overexpression has predictive utility in a randomized trial comparing CMF to CEF in premenopausal women with node positive breast cancer (NCIC CTG MA. 5). Presented at San Antonio Breast Cancer Symposium, San Antonio, TX, December 14-15, 2006

12. Rody A, Karn T, Gätje R, Ahr A, Solbach C, Kourtis K, Munnes M, Loibl S, Kissler S, Ruckhäberle E, Holtrich U, von Minckwitz G, Kaufmann M (2007) Gene expression profiling of breast cancer patients treated with docetaxel, doxorubicin, and cyclophosphamide within the GEPARTRIO trial: HER-2, but not topoisomerase II alpha and microtubule-associated protein tau, is highly predictive of tumor response. Breast 16(1):86-93

13. Slamon D, Eiermann W, Robert N, Pienkowski T, Martin M, Pawlicki M, Chan M, Smylie M, Liu M, Falkson C, Pinter T, Fornander T, Shiftan T, Valero V, Mackey J, Tabah-Fisch I, Buyse M, Lindsay MA, Riva A, Bee V, Pegram M, Press M, Crown J. on behalf of the BCIRG 006 Investigators, Phase III randomized trial comparing doxorubicin and cyclophosphamide followed by docetaxel (ACT) with doxorubicin and cyclophosphamide followed by docetaxel and trastuzumab (ACTH) with docetaxel, carboplatin and trastuzumab $(\mathrm{TCH})$ in HER2 positive early breast cancer patients: BCIRG 006 study, SABCS 2005, abstr. 1

14. Mueller RE, Parkes RK, Andrulis I, O'Malley FP (2004) Amplification of the TOP2A gene does not predict high levels of topoisomerase II alpha protein in human breast tumor samples. Genes Chromosomes Cancer 39(4):288-297

15. Fritz P, Cabrera CM, Dippon J, Gerteis A, Simon W, Aulitzky WE, van der Kuip H (2005) c-ErbB2 and topoisomerase IIalpha protein expression independently predict poor survival in primary human breast cancer: a retrospective study. Breast Cancer Res 7(3):R374-R384

16. Arriola E, Rodriguez-Pinilla SM, Lambros MB, Jones RL, James M, Savage K, Smith IE, Dowsett M, Reis-Filho JS (2007)
Topoisomerase II alpha amplification may predict benefit from adjuvant anthracyclines in HER2 positive early breast cancer. Breast Cancer Res Treat 106(2):181-189

17. Rody A, Holtrich U, Gaetje R, Gehrmann M, Engels K, von Minckwitz G, Loibl S, Diallo-Danebrock R, Ruckhäberle E, Metzler D, Ahr A, Solbach C, Karn T, Kaufmann M (2007) Poor outcome in estrogen receptor-positive breast cancers predicted by loss of plexin B1. Clin Cancer Res 13(4):1115-1122

18. Ruckhäberle E, Rody A, Engels K, Gaetje R, von Minckwitz G, Schiffmann S, Grösch S, Geisslinger G, Holtrich U, Karn T, Kaufmann M (2007) Microarray analysis of altered sphingolipid metabolism reveals prognostic significance of sphingosine kinase 1 in breast cancer. Breast Cancer Res Treat. doi: 10.1007/s10549-007-9836-9

19. Rody A, Holtrich U, Muller V, Gaetje R, Diallo R, Gehrmann M, von Minckwitz G, Engels K, Karn T, Kaufmann M (2006) c-kit: identification of co-regulated genes by gene expression profiling and clinical relevance of two breast cancer subtypes with stem cell like features. 2006 ASCO annual meeting proceedings part I. J Clin Oncol 24:622

20. Ahr A, Karn T, Solbach C, Seiter T, Strebhardt K, Holtrich U, Kaufmann M (2002) Identification of high risk breast-cancer patients by gene expression profiling. Lancet 359(9301):131-132

21. Miller LD, Smeds J, George J, Vega VB, Vergara L, Ploner A, Pawitan Y, Hall P, Klaar S, Liu ET, Bergh J (2005) An expression signature for p53 status in human breast cancer predicts mutation status, transcriptional effects, and patient survival. Proc Natl Acad Sci USA 102(38):13550-13555

22. Pawitan Y, Bjohle J, Amler L, Borg AL, Egyhazi S, Hall P, Han X, Holmberg L, Huang F, Klaar S, Liu ET, Miller L, Nordgren H, Ploner A, Sandelin K, Shaw PM, Smeds J, Skoog L, Wedren S, Bergh J (2005) Gene expression profiling spares early breast cancer patients from adjuvant therapy: derived and validated in two population-based cohorts. Breast Cancer Res 7(6):R953R964

23. Wang Y, Klijn JG, Zhang Y, Sieuwerts AM, Look MP, Yang F, Talantov D, Timmermans M, Meijer-van Gelder ME, Yu J, Jatkoe T, Berns EM, Atkins D, Foekens JA (2005) Gene-expression profiles to predict distant metastasis of lymph-node-negative primary breast cancer. Lancet 365(9460):671-679

24. Minn AJ, Gupta GP, Padua D, Bos P, Nguyen DX, Nuyten D, Kreike B, Zhang Y, Wang Y, Ishwaran H, Foekens JA, van de Vijver M, Massagué J (2007) Lung metastasis genes couple breast tumor size and metastatic spread. Proc Natl Acad Sci USA 104(16):6740-6745

25. Sotiriou C, Wirapati P, Loi S, Harris A, Fox S, Smeds J, Nordgren H, Farmer P, Praz V, Haibe-Kains B, Desmedt C, Larsimont D, Cardoso F, Peterse H, Nuyten D, Buyse M, Van de Vijver MJ, Bergh J, Piccart M, Delorenzi M (2006) Gene expression profiling in breast cancer: understanding the molecular basis of histologic grade to improve prognosis. J Natl Cancer Inst 98(4): 262-272

26. Loi S, Haibe-Kains B, Desmedt C, Lallemand F, Tutt AM, Gillet C, Ellis P, Harris A, Bergh J, Foekens JA, Klijn JG, Larsimont D, Buyse M, Bontempi G, Delorenzi M, Piccart MJ, Sotiriou C (2007) Definition of clinically distinct molecular subtypes in estrogen receptor-positive breast carcinomas through genomic grade. J Clin Oncol 25(10):1239-1246

27. Minn AJ, Gupta GP, Siegel PM, Bos PD, Shu W, Giri DD, Viale A, Olshen AB, Gerald WL, Massagué J (2005) Genes that mediate breast cancer metastasis to lung. Nature 436(7050):518-524

28. Desmedt C, Piette F, Loi S, Wang Y, Lallemand F, Haibe-Kains B, Viale G, Delorenzi M, Zhang Y, d'Assignies MS, Bergh J, Lidereau R, Ellis P, Harris AL, Klijn JG, Foekens JA, Cardoso F, Piccart MJ, Buyse M, Sotiriou C (2007) TRANSBIG consortium. Strong time dependence of the 76-gene prognostic signature for 
node-negative breast cancer patients in the TRANSBIG multicenter independent validation series. Clin Cancer Res 13(11): 3207-3214

29. The International Genomics Consortium (IGC). The expO project (Expression Project For Oncology) http://www.intgen.org/

30. Li C, Wong WH (2001) Model-based analysis of oligonucleotide arrays: expression index computation and outlier detection. Proc Natl Acad Sci USA 98(1):31-36

31. Irizarry RA, Bolstad BM, Collin F, Cope LM, Hobbs B, Speed TP (2003) Summaries of Affymetrix GeneChip probe level data. Nucleic Acids Res 31(4):e15

32. Foekens JA, Atkins D, Zhang Y, Sweep FC, Harbeck N, Paradiso A, Cufer T, Sieuwerts AM, Talantov D, Span PN, Tjan-Heijnen VC, Zito AF, Specht K, Hoefler H, Golouh R, Schittulli F, Schmitt M, Beex LV, Klijn JG, Wang Y (2006) Multicenter validation of a gene expression-based prognostic signature in lymph node-negative primary breast cancer. J Clin Oncol 24(11): $1665-1671$

33. Gong Y, Yan K, Lin F, Anderson K, Sotiriou C, Andre F, Holmes FA, Valero V, Booser D, Pippen JE Jr, Vukelja S, Gomez H, Mejia J, Barajas LJ, Hess KR, Sneige N, Hortobagyi GN, Pusztai L, Symmans WF (2007) Determination of oestrogen-receptor status and ERBB2 status of breast carcinoma: a gene-expression profiling study. Lancet Oncol 8(3):203-211

34. Bonnefoi H, Potti A, Delorenzi M, Mauriac L, Campone M, Tubiana-Hulin M, Petit T, Rouanet P, Jassem J, Blot E, Becette V, Farmer P, André S, Acharya CR, Mukherjee S, Cameron D, Bergh J, Nevins JR, Iggo RD (2007) Validation of gene signatures that predict the response of breast cancer to neoadjuvant chemotherapy: a substudy of the EORTC 10994/BIG 00-01 clinical trial. Lancet Oncol 8(12):1071-1078
35. Alexe G, Dalgin GS, Scanfeld D, Tamayo P, Mesirov JP, DeLisi C, Harris L, Barnard N, Martel M, Levine AJ, Ganesan S, Bhanot G (2007) High expression of lymphocyte-associated genes in node-negative HER2+ breast cancers correlates with lower recurrence rates. Cancer Res 67(22):10669-10676

36. de Azambuja E, Cardoso F, de Castro G Jr, Colozza M, Mano MS, Durbecq V, Sotiriou C, Larsimont D, Piccart-Gebhart MJ, Paesmans M (2007) Ki-67 as prognostic marker in early breast cancer: a meta-analysis of published studies involving 12,155 patients. Br J Cancer 96(10):1504-1513

37. Spyratos F, Ferrero-Poüs M, Trassard M, Hacène K, Phillips E, Tubiana-Hulin M, Le Doussal V (2002) Correlation between MIB-1 and other proliferation markers: clinical implications of the MIB-1 cutoff value. Cancer 94(8):2151-2159

38. Isaacs RJ, Davies SL, Sandri MI, Redwood C, Wells NJ, Hickson ID (1998) Physiological regulation of eukaryotic topoisomerase II. Biochim Biophys Acta 1400(1-3):121-137

39. Isaacs RJ, Harris AL, Hickson ID (1996) Regulation of the human topoisomerase IIalpha gene promoter in confluencearrested cells. J Biol Chem 271(28):16741-16747

40. Bagwell CB, Clark GM, Spyratos F, Chassevent A, Bendahl PO, Stål O, Killander D, Jourdan ML, Romain S, Hunsberger B, Baldetorp B (2001) Optimizing flow cytometric DNA ploidy and S-phase fraction as independent prognostic markers for nodenegative breast cancer specimens. Cytometry 46(3):121-135

41. Hannemann J, Kristel P, van Tinteren H, Bontenbal M, van Hoesel QG, Smit WM, Nooij MA, Voest EE, van der Wall E, Hupperets P, de Vries EG, Rodenhuis S, van de Vijver MJ (2006) Molecular subtypes of breast cancer and amplification of topoisomerase II alpha: predictive role in dose intensive adjuvant chemotherapy. Br J Cancer 95(10):1334-1341 